\title{
CRISE PLANETÁRIA, ESTADO \\ AMBIENTAL E ECOSSOCIALISMO: \\ APONTAMENTOS PARA UMA \\ APROXIMAÇÃO DE CONCEITOS
}

\section{João Alfredo Telles Melo}

Mestre em Direito (UFC). Professor do Curso de Direito da FA7. Vereador em Fortaleza (PSOL).

joaoalfredotellesmelo@gmail.com

Sumário: Introdução. 1. A crise ambiental planetária. 2. A ecologização da sociedade e do direito. 2.1. Do conservacionismo ao ecologismo dos pobres. 2.2. A ecologização do direito: o Estado de Direito Ambiental. 3. Ecossocialismo e direito: por uma aproximação de conceitos. Considerações finais

Resumo: O presente artigo pretende abrir uma discussão acerca dos impactos da atual crise ambiental planetária sobre a sociedade humana e de que forma os movimentos sociais, em especial os ecológicos, respondem ao que poderíamos chamar de crise civilizatória ou "policrise", em diálogo com a proposta de um nova sociabilidade: o socialismo ecológico ou ecossocialismo. A pretensão do trabalho não é, por óbvio, esgotar o assunto, que é novíssimo nas ciências sociais, mas, antes, instigar reflexões, na perspectiva de superação da crise em que a humanidade - e a vida, como um todo - está mergulhada hoje.

Palavras-chave: Crise Ambiental. Movimento Ecológico. Ecossocialismo

\section{INTRODUÇÃo}

O presente trabalho pretende fazer uma discussão sobre os impactos da atual crise ambiental planetária sobre a sociedade humana e o direito. Pretende, com isso, a partir do que se conceitua de uma crise planetária, com característica de "policrise", analisar como os movimentos ambientais a ela reagiram e como influenciaram o direito, em especial, o Direito Ambiental, em diálogo finalmente com a nova proposta do socialismo ecológico, ou ecossocialismo..

No primeiro tópico, procura-se compreender que crise planetária é essa, suas principais manifestações e suas explicações, não só aquelas concer- 
nentes às causas ambientais, mas, também, ideológicas, políticas e econômicas. Ou seja, se a crise climática - manifestação mais visível, mas, não única - do impasse civilizacional em que a sociedade humana está imersa tem causas antropogênicas, e não naturais, procura-se entender que organização societária é essa que originou a crise.

No segundo capítulo, analisa-se a ecologização da sociedade e do direito. No primeiro caso, apresentam-se quais as principais concepções do ecologismo, sua relação com a sociedade capitalista e sua influência no direito. Quanto a este, sua ecologização é vista a partir de um novo marco hermenêutico que procura construir o conceito de Estado de Direito Ambiental, como uma evolução do Estado Social e do Estado Democrático de Direito, de onde ele procede.

Finalmente, no terceiro e último tópico, faz-se uma apresentação do que seria uma sociedade ecológica e socialista, o ecossocialismo, como superação do capitalismo e do socialismo produtivista, e o seu diálogo com novos conceitos, princípios e institutos jurídicos, em especial, aqueles tributários do que se denomina hoje a civilização do "Bem Viver", originária dos povos indígenas andinos, que, inclusive, encontram-se materializados em algumas cartas políticas, como a Constituição boliviana.

A pretensão do artigo não é, por óbvio, esgotar o assunto, que é novíssimo nas ciências sociais, em especial, no Direito, mas, tão somente, aproximar conceitos como os de Estado de Direito Ambiental e Ecossocialismo. Tudo isso, na perspectiva de superação da crise em que a humanidade - a vida, como um todo - está mergulhada hoje.

\section{A Crise Ambiental Planetária}

Crê-se não haver dúvidas de que o mundo está imerso em uma crise ambiental planetária de proporções ainda não vividas pela sociedade humana. Sua face mais visível, mas não única, são o superaquecimento da Terra e as mudanças climáticas. A divulgação, em fevereiro de 2007, do $4^{\circ}$. Relatório de Avaliação das Mudanças Climáticas do IPCC (Painel Intergovernamental de Mudanças Climáticas, em sua sigla em inglês), causou um grande impacto, dadas suas gravíssimas conclusões, ao observar, sobre as mudanças no clima e seus efeitos, que o aquecimento do sistema climático é inequívoco e que suas causas, ligadas à emissão de gases do efeito estufa (GEEs), são antropogênicas e não naturais e que seus impactos sobre a natureza e a sociedade já se fazem sentir (disponível em: http://www.ipcc.ch/publications_and_data/ar4/syt/en/spm.htm).

Marengo (2006, p.25), pesquisador do Instituto Nacional de Pesquisas Espaciais (INPE) e membro do IPCC, observa que, apesar do planeta ter sempre passado "por ciclos naturais de aquecimento e resfriamento [...] atualmente, 
a atividade industrial está afetando o clima terrestre na sua variação natural, o que sugere que a atividade humana é fator determinante no aquecimento".

Não há um dia em que não se observe a ocorrência em qualquer parte do mundo de algum fenômeno climático-ambiental extremo: secas, tufões, enchentes etc., fenômenos que têm sido cada vez mais intensos e recorrentes, a ponto de um termo do vocabulário de guerra ter sido adaptado para o repertório ecológico: o "refugiado climático" ou "refugiado ambiental", que já se conta em milhões no planeta. A Cruz Vermelha Internacional, que publicou, em 2001, o "Relatório Mundial de Desastres", estima a existência de 25 milhões de refugiados climáticos atualmente, com uma projeção de mais de 200 milhões em 2050 (Disponível em: http://www.ifrc.org/publicat/wdr2001/).

O objetivo deste artigo não é confrontar as posições acerca dos estudos e previsões do IPCC (derretimento das geleiras, elevação do nível dos mares, desertificação etc.), onde, se, por um lado, os chamados "céticos", ou melhor, "negacionistas", ainda que em minoria na comunidade científica, contestam esses dados, outros há, como Lovelock (2010), autor da Teoria Gaia, que considerem terem sido esses mesmos dados subestimados, uma vez que a velocidade das mudanças no clima e no planeta são imensamente mais graves.

No entanto, como já aludido antes, o aquecimento global e as mudanças climáticas são apenas a face mais visível de uma crise maior, que se relaciona à atual configuração do modo de produção capitalista, com seu modelo de desenvolvimento, a um só tempo fossilista e produtivista-consumista, e um modo de vida das elites econômicas mundiais baseado no consumo perdulário, que são, a um só tempo, ambientalmente insustentáveis e socialmente injustos; não só em escala regional ou nacional, mas em nível planetário.

Foster (2005), autor do clássico "A Ecologia de Marx: materialismo e natureza", em um instigante artigo, intitulado "Organizar a Revolução Ecológica" (disponível em: http://resistir.info/mreview/revolução_ecologica.html), lista os sinais de advertência da crise ambiental global, a demonstrar a insustentabilidade do percurso da humanidade nestes tempos atuais, dentre os quais se destacam, além do aquecimento global, os que se seguem:

O planeta está a enfrentar escassez de água global devido à extração de aquíferos insubstituíveis, os quais constituem a maior parte do abastecimento de água fresca do mundo. Isto coloca uma ameaça à agricultura global, a qual tornou-se uma economia bolha baseada na exploração insustentável das águas subterrâneas. Uma em cada quatro pessoas no mundo de hoje não tem acesso à água potável (Bill McKibben, New York Review of Books, 25/Setembro/2003).

Dois terços dos bancos pesqueiros do mundo estão atualmente a ser capturados à sua capacidade máxima ou acima dela. Durante o último meio 
século de pesca predatória nos oceanos do mundo, 90 por cento foram eliminados (Worldwatch, Vital Signs 2005).

A extinção de espécies é a mais elevada em 65 milhões de anos, com a perspectiva de extinções progressivas à medida que forem removidos os últimos remanescentes dos ecosistemas intactos. A taxa de extinção já está a aproximar-se 1000 vezes da "referência" ("benchmark") ou taxa natural (Scientific American, Setembro/2005). Cientistas localizaram 25 pontos quentes sobre a Terra que representam 44 por cento de todas as espécies de plantas vasculares e 35 por cento de todas as espécies em quatro grupos vertebrados, embora ocupem apenas 1,4 por cento da superfície da terra mundial. Todos esses pontos quentes estão agora ameaçados de aniquilação rápida devido a causas humanas (Nature, 24/Fevereiro/2000).

De acordo com um estudo publicado em 2002 pela National Academy of Sciences, a economia mundial excedeu a capacidade regenerativa da Terra em 1980 e em 1999 ultrapassou-a em 20 por cento. Isto significa, segundo os autores do estudo, que "seriam precisas 1,2 Terra, ou uma Terra por cada 1,2 ano, para regenerar o que a humanidade utilizou em 1999" (Matthis Wackernagel, et. al, Tracking the Ecological Overshoot of the Human Economy, Proceedings of the National Academy of Sciences, 09/Julho/2002).

Na verdade, o que ocorre é que, como adverte um manifesto assinado por 29 cientistas mundiais e publicado na revista Nature, de 24.09.2009 (conforme noticia Rogério Tuma, na Carta Capital do dia seguinte, em sugestivo artigo intitulado "Antropoceno, a era da destruição"), "as atividades diárias dos 6 bilhões de humanos resultam por si em uma força geofísica capaz de mudar completamente a Terra, equivalente às grandes forças da natureza" (acessível em http://www.cartacapital.com.br/app/materia.jsp? $a=2 \& a 2=6 \& i=5132$ ).

Ali, se denuncia que, pelo menos, três limites biofísicos de sustentabilidade do planeta já foram ultrapassados: o equilíbrio climático (aquecimento global), os resíduos orgânicos de nitrogênio e a crise da biodiversidade, a qual os cientistas já denominam de a grande "sexta extinção de espécies". Outros seis limites podem ser rompidos na próxima década, se nada for feito.

Morin e Kern (2005, p. 94), ainda na década de 90, do século passado, ao analisar a "agonia planetária" conceituam o estado da arte da "Terra-Pátria" e da "Humanidade-comunidade de destino" como "policrise" ou "conjunto policrístico", num entrelaçamento das crises do desenvolvimento, da modernidade e das sociedades; uma crise civilizatória, portanto.

Configurada a crise ("policrise"), que é social, ambiental e planetária, é preciso que se advirta, por oportuno, que há uma disputa de natureza ideológica - ideologia aqui como "visão de mundo" - sobre o entendimento das causas dessa crise, que confronta, em matizes diferenciados, capitalistas "verdes" versus "ecossocialistas", ou seja, a disputa sobre projetos de sociedade (e de civilização, portanto), o que terá impactos sobre a superestrutura jurídica, como se verá adiante. 
A compreensão dos que se reivindicam herdeiros da utopia (no sentido positivo do termo) igualitária do Século XIX, à qual se agrega o ecologismo da contemporaneidade, é a de que, nas precisas palavras do Manifesto Ecossocialista Internacional, "o atual sistema capitalista não pode regular, muito menos superar, as crises que deflagrou. Ele não pode resolver a crise ecológica porque fazê-lo implica em colocar limites ao processo de acumulação - uma opção inaceitável para um sistema baseado na regra "cresça ou morra" (Löwy, 2005, p. 86).

Além desse paradoxo - a imposição de limites a um sistema, cuja lógica é o crescimento sem limites, daí o surgimento do atualíssimo debate sobre decrescimento, presente em Latouche (2011) e em Kempf (2010),- serão encontradas, pelo menos, mais duas outras grandes contradições entre o "ethos" do sistema produtor de mercadorias e os processos ecológicos naturais: a apropriação privada da natureza - vista apenas como "recurso" natural - e sua incorporação como mercadoria, o que só é possível se ela se tornar escassa.

Porto-Gonçalves (2004, p. 67), ao falar desses paradoxos, de forma magistral, assim os desvenda;

\begin{abstract}
Além disso, privar é tornar um bem escasso e, dessa forma, numa sociedade que tudo mercantiliza, um bem só tem valor econômico se é escasso. O princípio da escassez, assim como a propriedade privada que lhe é essencial, é que comanda a sociedade capitalista e suas teorias liberais de apropriação dos recursos naturais. Ocorre que a idéia de riqueza é o contrário de escassez e aqui reside uma das maiores dificuldades da economia mercantil: incorporar a natureza como riqueza, como algo abundante, um bem comum (grifou-se).
\end{abstract}

É aquilo que a teoria marxiana tão bem distingue entre "valor
de uso" e "valor de troca". Para se tornar mercadoria, o bem de uso se transforma em valor de troca; para ter valor de troca, é preciso que não seja abundante. Aqui, como advertem os teóricos do Ecossocialismo, a riqueza tem definições distintas e opostas. Foster, em seu artigo já aqui citado (on line já citado), se vale de Epicuro ("Principal Doctrines"), para expor o paradoxo: "Quando medida pelo propósito natural da vida, a pobreza é grande riqueza, riqueza ilimitada é grande pobreza".

Trata-se, portanto, não só de uma crise ambiental e social, mas uma crise da própria civilização do capital, de sua lógica econômica, de seu modelo de desenvolvimento, de seu modo de vida e de seus valores, que engendram, a um só tempo, uma desigualdade social cada vez mais abissal entre uma "oligarquia global"- cuja renda de seus 500 mais ricos supera a dos 416 milhões mais pobres - e os mais de 1 bilhão de humanos que sobrevivem com menos de 1 dólar por 
dia, e a destruição acelerada das bases naturais que sustentam a vida em nosso planeta (Kempf, 2010, p. 65).

Isso compreendendo, com Foster (2005, p. 331), que a relação humana com a natureza é "mediada pela sociedade, e a sociedade é o meio ambiente humano imediato. Mas, a sociedade tem na natureza o seu meio ambiente", e que, nas palavras de Stucka (1998, p. 25), o Direito é "um sistema de relações sociais ou, ainda, que trata de uma determinada ordem social", importante investigar quais as implicações ocorridas no mundo sociojurídico a partir da crise ambiental em que o planeta está mergulhado.

\section{A Ecologização da Sociedade e do Direito}

Não haveria como todos esses fatos vinculados à crise ambiental planetária permanecerem alheios à sociedade humana e à(s) sua(s) superestrutura(s) jurídica(s). Daí que, tomando emprestado (e ampliando) a percepção, proposta por Benjamim (2008, p. 57), de "ecologização" constitucional, tratar-se-á como, nos últimos anos, ocorreu uma "ecologização" da sociedade e, por consequência, do Direito. Assim, far-se-á um breve percurso pelos movimentos ecológicos, na sua relação com o sistema do capital, para, em seguida, volver-se à ecologização do Direito.

\subsection{Do CONSERVACIONISMO AO ECOLOGISMO DOS POBRES}

É cediço, entre os que militam no jus-ambientalismo, a compreensão de que, ao lado da Ciência e de suas descobertas, são os movimentos sociais ambientais as principais fontes materiais do Direito Ambiental. Portanto, a gênese, a evolução e as principais correntes do ambientalismo permitem desvendar as modificações principais por que passou o Direito do Ambiente nas últimas décadas (para não ter que recuar a um horizonte histórico muito remoto).

Ainda que haja diferentes formas de abordar e classificar os movimentos ecológicos, há um consenso, entre os autores, de que foi o "conservacionismo", que Alier (2007, p. 22) denomina de "culto à vida silvestre" - pela "defesa da natureza intocada, o amor aos bosques primários e aos cursos dágua" -, a primeira forma de organização do ambientalismo, remontando à criação dos parques nacionais, como o de Yellowstone, nos Estados Unidos da América, em 1872, e o de Itatiaia, no Brasil, em 1937.

Do ponto de vista social, ainda existem grandes organizações atuan-tes, como o IUCN, International Union for Conservation of Nature e o WWF, World Wildlife Fund. A marca dessa corrente do ecologismo na legislação se 
encontra no reconhecimento da necessidade de criação de unidades de conservação de proteção integral, tal qual está prevista na Lei 9985/2000, que instituiu o Sistema Nacional de Unidades de Conservação (SNUC).

No entanto, como bem observa Alier (2007, p. 22), "o culto ao silvestre não ataca o crescimento econômico enquanto tal. Até mesmo admite sua derrota na maior parte do mundo industrializado. Porém, coloca em discussão uma 'ação de retaguarda', que [...] visa a preservar e manter o que resta dos espaços de natureza original situados fora da influência do mercado".

Cumpre, apenas, aqui advertir que, ainda que se concorde com essa crítica, posto que o movimento, no geral, não enfrenta a organização societária responsável pela destruição da "vida silvestre", a criação de unidades de conservação, em alguns casos, confronta-se com o capital imobiliário e com o agronegócio, e, em outros, é fundamental para resguardar ecossistemas e espécies ameaçadas.

Se ainda podem ocorrer essas disputas com setores do capital, principalmente em função de conflitos sobre a propriedade e uso do território, a segunda corrente anotada por Alier (2007), conforma-se, plenamente, ao modo de produção capitalista, sendo mesmo uma resposta deste à crise planetária, a partir da lógica do mercado: é o chamado "evangelho da ecoeficiência".

A "ecoeficiência" - com sua visão econômico-tecnicista-considera que somente o desenvolvimento científico-tecnológico, voltado para "limpar ou remediar a degradação causada pela industrialização" (Alier, 2007, p. 28), dará conta da crise ambiental, sendo considerada como o vínculo empresarial com o desenvolvimento sustentável. No Brasil, o Conselho Empresarial Brasileiro para o Desenvolvimento Sustentável, o CEBDS, "uma coalizão dos maiores e mais expressivos grupos empresariais do Brasil, com faturamento anual correspondente a 40\% do PIB nacional" é a representação do ecocapitalismo ou capitalismo verde no país (cf. www.cebds.org.br).

Mesmo que se reconheça que essa corrente possibilita um debate importante sobre as chamadas tecnologias limpas, dentre outros aspectos da ecoeficiência, ela ainda está presa ao que Morin e Kern (2005, p. 92) denominam de "mito do desenvolvimento". Para ambos, a humanidade precisa se libertar do "paradigma pseudorracional do homo sapiens faber, segundo o qual ciência e técnica assumem e levam a cabo o desenvolvimento humano".

É no seio da terceira corrente classificada por Alier (2007) que se encontram as críticas mais profundas ao modo de produção e ao modelo de desenvolvimento capitalista: o "ecologismo dos pobres", "ecologismo popular" ou "movimento de justiça ambiental". Mas, poder-se-ia também aduzir o que Santilli (2005, p. 31) denomina de "socioambientalismo". Esses movimentos assinalam diz Alier (2007, p. 33) - que, "desgraçadamente, o crescimento econômico implica 
maiores impactos no meio ambiente, chamando a atenção para o deslocamento geográfico de recursos e das áreas de descarte dos resíduos”.

Não é objetivo deste trabalho fazer uma análise exaustiva dos movimentos ecologistas, mas, é importante ressaltar que, a despeito de que tenham sido classificados em uma única corrente, há diferenças importantes entre os movimentos de direitos civis estadunidenses que denunciaram, sob o selo da "Justiça Ambiental", o chamado "racismo ambiental" (Acselrad, 2009, p. 20) que é a "imposição desproporcional - intencional ou não - de rejeitos perigosos às comunidades de cor" - e o "socioambientalismo", que surgiu no Brasil, a partir de uma importante articulação entre os movimentos sociais e o movimento ambientalista.

A maior referência desse movimento foi o líder seringueiro e mártir ambientalista Chico Mendes (século XX), que compreendeu, na própria pele, a indissolubilidade da luta em defesa da terra e do trabalho dos extrativistas e a preservação da floresta amazônica. Essa coalizão, que se materializou na "Aliança dos Povos da Floresta" (seringueiros, índios, ribeirinhos, quilombolas), inscreveu definitivamente em nossa legislação as "reservas extrativistas" e outros tipos de unidades de conservação de uso sustentável.

Ainda que ocorram essas diferenças e nuances, pode-se considerar como Alier (2007, p. 340), que o ecologismo dos pobres, a justiça ambiental e o socioambientalismo (acrescentar-se-ia, a partir de Santilli, 2005), são as "principais forças em prol da sustentabilidade", posto que, por intermédio de suas lutas, não se pretende resolver os conflitos ambientais, mas, sim, exacerbá-los "para avançar na direção de uma economia ecológica". E socialista, aduzir-se-ia; ecossocialista, portanto.

\subsection{A ecologização do Direito: o Estado de Direito Ambiental}

O Direito, como superestrutura, não ficaria imune a todas essas transformações, engendradas, a um só tempo, pela crise ambiental e pela resposta dos diversos movimentos sociais e ambientais, em seus variados matizes, a ponto de Canotilho (2008, p. 5) asseverar que se pode falar hoje de um "Estado de direito ambiental e ecológico", arrematando que "o Estado de direito, hoje, só é Estado de direito se for um Estado protetor do ambiente e garantidor do direito ao ambiente".

É o que Benjamin (2008, p. 72) chama de "ecologização da Constituição", o que se irradia sobre os seus princípios, regras e institutos, como é o caso da propriedade e da função social, com a instituição de "um regime de exploração limitada e condicionada (= sustentável) da propriedade e agregar à função social da propriedade, tanto urbana como rural, um forte e explícito componente ambiental". 
Mas, é através do que Belchior (2011, p. 196) denomina de "। Hermenêutica Jurídica Ambiental" - que, "por meio de princípios de interpretação" objetiva "a busca de soluções justas e constitucionais adequadas para a interpretação de normas ambientais", que se chegou à fórmula político-jurídica do Estado de Direito Ambiental.

Um desses princípios, considerado por Belchior (2011) como "ás na manga" do intérprete, é aquele que se denomina "in dubio pro natura" ou "in dubio pro ambiente", ou seja, uma interpretação mais amiga do ambiente, advertindo-se, com a autora, que ele não seria "absoluto", posto que deve ser ponderado com outros princípios interpretativos.

Ainda que não seja objetivo deste texto fazer um exame exaustivo acerca dos caminhos interpretativos para a compreensão do Direito Ambiental, é importante, no diálogo com a hermenêutica proposta por Belchior, trazer à colação, a principiologia proposta por Coelho (in http://revistas.unipar.br/juridica/article/ viewFile/2262/1863), através das 11 teses abaixo transcritas, para que possamos ter conhecimento de uma visão que poderia ser considerada mais "radical" (dado o seu caráter "ecocêntrico") de defesa da natureza:

1. O direito subjetivo a um ambiente natural saudável, ou seja, o direito subjetivo ambiental tem status de direito fundamental, por ser extensão do direito à vida, pressuposto de todos os demais direitos.

2. O direito subjetivo ambiental inclui-se entre os direitos humanos.

3. A proteção ambiental diz respeito a um bem jurídico transcendente, que interessa a todos os homens como projeção de sua dignidade, e ipso facto, às nações e à humanidade.

4. O ambiente natural é um valor em si que deve ser preservado, não devendo estar submetido a interesses puramente humanos.

5. Os seres vivos da natureza são titulares dos direitos que a própria natureza lhes concedeu, os quais devem ser respeitados pelos seres humanos.

6. As leis ambientais, ainda que no contexto do direito privado, são sempre imperativas (jus cogens).

7. A responsabilidade por dano ambiental é sempre objetiva.

8. A interpretação, integração e aplicação das leis ambientais será sempre direcionada, em direito público, como em direito privado, para a proteção dos interesses difusos.

9. O conceito de vítima de dano ambiental identifica-se com a proteção dos interesses difusos, ainda que decorrente da inobservância de normas de direito privado.

10. Em caso de conflitos normativos, a solução será sempre a que favorecer a proteção ambiental.

11. IN DUBIO PRO NATURA. 
Voltando ao Estado de Direito Ambiental é, pois, este ainda considerado uma construção teórico-interpretativa, que parte da compreensão de que "os recursos ambientais são finitos e antagônicos com a produção de capital e consumo existentes", nas palavras de seus principais teóricos, Leite e Ayala (2010, p. 28).

Citando Capella, Leite e Ayala (2010, p. 31) assim conceituam o Estado Ambiental: a "forma de Estado que se propõe a aplicar o princípio da solidariedade econômica e social para alcançar um desenvolvimento sustentável, orientado a buscar a igualdade substancial entre os cidadãos, mediante o controle jurídico do uso racional do patrimônio natural".

Em outro texto, Leite (2008, p. 151/2) lista "cinco funções fundamentais da discussão do Estado de Direito Ambiental", as quais serão apenas aqui citadas: 1) Moldar formas mais adequadas para a gestão dos riscos e evitar a irresponsabilidade organizada; 2) Juridicizar instrumentos contemporâneos preventivos e precaucionais, típicos do Estado pós-social; 3) Trazer a noção, ao campo do Direito Ambiental, de direito integrado; 4) Buscar a formação da consciência ambiental; e 5) Propiciar maior compreensão do objeto estudado.

No mesmo estudo, vê-se que os princípios estruturantes no Estado de Direito Ambiental são bem conhecidos da doutrina, quais sejam, aqueles vinculados à democracia (princípios da participação, cidadania, democracia e cooperação ambiental), à precaução (princípios da atuação preventiva e da precaução) e à responsabilidade (princípios do poluidor-pagador e da responsabilidade).

A concepção do Estado de Direito Ambiental, como se disse alhures, irradia, como não poderia deixar de ser, também seus efeitos para os institutos jurídicos, como é o caso da propriedade, conforme se vê não somente na Constituição Federal, no art. 225, caput, quando fala que o meio ambiente é "bem de uso comum do povo" ou no art. 186, II, ao condicionar a função social da propriedade à "utilização adequada dos recursos naturais disponíveis e preservação do meio ambiente", conceito este ampliado, agora, pelo novo Código Civil, para o instituto como um todo, pois, em seu art. 1228, condiciona o exercício do direito de propriedade, à preservação da "flora, fauna, belezas naturais, equilíbrio ecológico e patrimônio histórico e artístico, bem como evitada a poluição do ar e das águas".

Estar-se-ia diante da função socioambiental da propriedade ou como conceituam Belchior e Matias (in http:www.conpedi.org.br/manaus/arquivos/anais/Brasília/07_216.pdf), da função ambiental autônoma da propriedade, pois, em sua concepção, à leitura do dispositivo acima referido, "constata-se que o ambiente sadio não está dentro da função social da propriedade. $\mathrm{O}$ legislador foi mais longe, ao impor uma função ambiental autônoma, nova, gerando outras obrigações ao proprietário de qualquer bem além daquelas já previstas com a função social". 
Esse esforço interpretativo - ao qual se poderia aduzir, ainda que só para não deixar de citá-los, os princípios do mínimo existencial ecológico e da proibição do retrocesso ambiental - é extremamente importante, pois, em última análise, são instrumentos poderosos nas mãos do intérprete para fazer face a esse processo de verdadeira destruição ambiental em que se encontram hoje a natureza e a humanidade.

No entanto, Leite (2008, p. 158), em sua precisa digressão sobre o Estado de Direito Ambiental, alerta para o fato de que "a grande e, talvez, a maior dificuldade em construir um Estado de Direito Ambiental é transformá-lo em um Estado de Justiça Ambiental".

A questão que se coloca, portanto, é que, ainda que, mesmo reconhecendo a extrema validade desse percurso interpretativo que procura construir, na concretude (e não só na abstração), o Estado de Direito Ambiental - um avanço considerável frente às fórmulas políticas que lhe deram origem do Estado Social e do Estado Democrático de Direito - ele ainda se encontra circunscrito aos marcos do capitalismo, mitigado, é verdade, mas, que garante, como princípios da ordem econômica, a livre iniciativa (com limites, óbvio) e a propriedade privada (com suas funções social e ambiental, reconheça-se).

Assim é que - uma vez reconhecida a extrema gravidade e urgência da crise ambiental planetária e a necessidade de se ter, também, respostas mais graves e urgentes, no que respeita à imposição de limites fortes ao desenvolvimentismo desvairado, ao consumismo perdulário e à obsolescência programada, bem ainda à necessidade de proteção da natureza ameaçada e dilapidada, ao imperativo ético da justiça social e ambiental, que possa resolver os gravíssimos índices de pobreza e degradação - poder-se-ia considerar esse instrumental teórico-interpretativo, mesmo que eticamente comprometido com um novo ethos humanístico e ambiental, apto a dar conta do desafio de reverter esse quadro verdadeiramente apocalíptico?

Como transitar do Estado de Direito Ambiental para o Ecossocialismo? Como superar a sociedade do capital e construir a sociedade ecológica, democrática e socialista? Haveria uma teoria de um programa de transição - a um só tempo ético, político, ideológico, econômico, ecológico, cultural e jurídico - da atual sociedade para uma de novo tipo? Poder-se-ia pensar em uma Teoria Ecossocialista do Direito?

A intenção deste artigo não é trazer as respostas, até porque o debate sobre o Ecossocialismo é recentíssimo e sua formulação ainda não chegou aos aspectos da superestrutura jurídica. O que se pretende é fazer uma aproximação de conceitos. Para tanto é preciso ver o que se tem formulado acerca do que seria essa sociedade socialista e ecológica. 


\section{Ecossocialismo e Direito: por UMA APROXimaÇão DE CONCEITOS}

Um dos mais importantes formuladores da teoria ecossocialista, Löwy (2005, p. 42), encontra no socialismo e na ecologia objetivos comuns, posto "que implicam questionar a autonomização da economia, do reino da quantificação da produção como um objetivo em si mesmo, da ditadura do dinheiro (...) Ambos pedem valores qualitativos: o valor de uso, a satisfação das necessidades, a igualdade social para uns, a preservação da natureza, o equilíbrio ecológico para outros".

O seu viés democrático, socialista e ecologista o fazem combater tanto a sociedade de mercado capitalista, fundada no individualismo, no consumismo, na busca desenfreada do lucro, na apropriação privada dos meios de produção, como também as experiências do chamado "socialismo real", posto que sua matriz produtivista e a concorrência com os países capitalistas, em governos conduzidos por burocracias antidemocráticas, causaram, nos países do Leste, danos e impactos ambientais para a natureza e a população daqueles países.

Löwy (2005,p. 42), citando James O'Connor, diz que o objetivo do socialismo ecológico é a construção de uma "sociedade ecologicamente racional fundada no controle democrático, na igualdade social, e na predominância do valor de uso". E acrescenta: "tal sociedade supõe a propriedade coletiva dos meios de produção, um planejamento democrático que permita à sociedade definir os objetivos da produção e os investimentos, e uma nova estrutura tecnológica das forças produtivas".

A queda do Muro de Berlim, ainda que existam hoje países que, de forma bastante diversa (como Cuba, China e Coreia do Norte) se reivindicam socialistas e ainda que ela, a queda, seja propagandeada, pelos pensadores liberais, como o "Fim da História" e uma vitória inconteste da sociedade capitalista, na verdade, representou o fim de um modelo que era, a um só tempo, politicamente antidemocrático, economicamente ineficiente e ecologicamente insustentável.

Por outro lado, a "policrise" social, ambiental e civilizatória da sociedade produtora de mercadorias desmente a tese de que o capitalismo foi vitorioso, tantos são os mortos em combate e tamanha é a catástrofe ambiental que representa a atual era das mudanças climáticas.

Abrem-se, portanto, as janelas para um socialismo que seja renovado com o ecologismo popular, com a ética humanista, com a radicalidade democrática e, também, com a contribuição tanto dos que se reivindicam da teoria marxiana, além ainda de novos sujeitos históricos, como as populações tradicionais, que resgatam seus valores ancestrais de relação com a natureza e constroem novos conceitos, instrumentos políticos e institutos jurídicos. 
No primeiro caso, vale citar, ainda que rapidamente, a reflexão de Harribey (in http://resistir.info/ambiente/ecologia_politica.html) quando afirma que, "a relação entre ecologia e justiça social contém pelo menos três exigências fundamentais de ordem teórica e prática", a saber: uma nova teoria da justiça, a definição dos direitos de propriedade coletivos e a partilha dos ganhos de produtividade, com a diminuição da jornada de trabalho, para melhorar a qualidade de vida.

Quanto aos novos sujeitos, merecem um olhar especial as formulações vindas das populações indígenas dos Andes, na América do Sul, em especial, na Bolívia, onde há um presidente índio aymara, e, também, no Equador e no Peru. Boaventura de Sousa Santos, com a argúcia e atenção que lhe são peculiares, já enxerga, nessa região, a gestação do "Socialismo do Bem Viver", pois, em suas palavras, há duas transições no continente hoje: "La transición del capitalismo al socialismo y la transición del colonialismo a la autodeterminación, al fin del racismo, a la posibilidad que tenemos de la convivencia de diferentes nacionalidades dentro del mismo Estado" (in http://www.alames.org/documentos/ socialismobov.pdf).

Mesmo que se concorde com a consigna do Manifesto Ecossocialista Internacional, de que "o ecossocialismo será universal e internacional ou não será", não se pode desconhecer a importância de processos sociais como o da Bolívia, por exemplo, que vive uma revolução cultural, de transição do colonialismo para a autodeterminação, incorporando valores indígenas, se reconhecendo um Estado plurinacional (e plurilinguístico), comunitário, democrático e intercultural.

Sua Constituição Política do Estado, promulgada em 2009, traz alguns elementos importantes na perspectiva de uma sociedade ecossocialista, dentre os quais se apontam:

1. No art. 30, os direitos das nações e povos indígenas originários campesinos, a saber, dentre outros: à identidade cultural e sua própria cosmovisão, à titulação coletiva de terras e territórios; à proteção dos seus lugares sagrados; a viver em meio ambiente sadio; à propriedade intelectual coletiva de seus saberes, ciências e conhecimentos; à gestão territorial autônoma etc.

2. No art. 33, ao tratar do direito das pessoas a um meio ambiente saudável, protegido e equilibrado, estabelece que o exercício desse direito deve permitir, não só aos indivíduos e coletividades das presentes e futuras gerações, mas também a outros seres vivos, a se desenvolverem de forma normal e permanente;

3. No art. 393, reconhece três tipos de propriedade da terra; a privada individual e comunitária e a coletiva, especificando inclusive um limite máximo para o tamanho delas (5.000 hectares).

Não é à toa que a Bolívia sediou, em Cochabamba, em abril de 2010, a Conferência Mundial dos Povos sobre o Câmbio Climático e os Direitos da Mãe Terra, a qual aprovou um projeto de "Declaração Universal 
dos Direitos da Mãe Terra" cujos artigos foram inspirados no ecocentrismo da cosmovisão andina.

Evidentemente, uma leitura pormenorizada da Declaração, bem como da Constituição boliviana, permitiria uma análise bem mais aprofundada desses novos valores, conceitos, princípios, direitos, institutos. Não é, porém, o objetivo deste pequeno artigo, que se pretende apenas provocativo, no sentido de buscar uma teoria e uma práxis jurídica, no viés ecossocialista; daí serem ainda apontamentos para uma tentativa de aproximação de conceitos.

\section{Considerações Finais (PARA não CONCLUIR)}

A crise civilizacional sócio-climático-ambiental demanda da sociedade uma ruptura radical com essa civilização, seus valores, sua economia, sua cultura e sua política, para que se possa pensar na continuidade da vida em nosso planeta-pátria. A importância das lutas e movimentos sociais, ecológicos, socioambientais e ecossocialistas é fundamental na gestação de um novo Estado, ainda que de transição, e de um novo Direito.

Esse novo Direito pode beber tanto na tradição do socialismo libertário e antiburocrático, como nas lutas do ecologismo popular, do socioambientalismo e da justiça social em todas as partes do mundo, onde as experiências originais dos povos tradicionais, que resgatam valores ancestrais, em que a natureza, vista como mãe, não pode nunca ser encarada como um mero recurso, como matéria-prima para os produtos, como mercadoria, como algo que tenha apenas valor de troca.

O Ecossocialismo ainda é uma promessa, uma aposta, mas, é uma necessidade premente para garantir a sobrevivência da humanidade, enquanto espécie e sociedade, e da vida na Terra. Esse ser em processo, em construção, permite que se possa dialogar com as experimentações jurídico-políticas cujas premissas são a igualdade social, a sustentabilidade ecológica, e a defesa da diversidade em seus aspectos biológico, social, étnico e cultural.

Afinal, o que se coloca para a humanidade é o desafio da constituição dessa nova sociedade que possa vir a ser, a um só tempo, politicamente democrática, socialmente justa e igualitária, cultural e etnicamente diversa e ambientalmente sustentável. A sociedade ecossocialista. 


\section{REFERÊNCIAS}

ACSELRAD, Henri; MELLO, Cecília Campllo do A.; BEZERRA, Gustavo das Neves. O que é justiça ambiental. Rio de Janeiro: Garamond, 2009.

ALIER, Joan Martinez. O ecologismo dos pobres: conflitos ambientais e linguagem de valoração. Trad. Maurício Waldman. São Paulo: Contexto, 2007.

BELCHIOR, Germana Parente Neiva. Hermenêutica e Meio Ambiente: uma proposta de Hermenêutica Jurídica Ambiental para a efetivação do Estado de Direito Ambiental. São Paulo: Saraiva, 2011.

; Matias, João Luis Nogueira. A Função Ambiental da Propriedade. http://www.conpedi.org.br/manaus/arquivos/anais/brasilia/07_216.pdf CANOTILHO, José Joaquim Gomes. Direito Constitucional Ambiental Português e da União Europeia. In CANOTILHO, José Joaquim Gomes; LEITE, José Rubens Morato (orgs.). Direito Constitucional Ambiental Brasileiro 2a ${ }^{\mathrm{a}}$. Ed. rev. São Paulo: Saraiva, 2008.

Conferencia Mundial de los Pueblos sobre el Cambio Climático y los Derechos de la Madre Tierra: http://cmpcc.org/derechos-madre-tierra/

Conselho Empresarial Brasileiro para o Desenvolvimento Sustentável: www. cebds.org.br

COELHO, Luis Fernando. Dogmática, Zetética e Crítica do Direito Ambiental. http://revistas.unipar.br/juridica/article/viewFile/2262/1863

HARRIBEY, Jean-Marie. Marxismo ecológico ou ecologia política marxiana. http://resistir.info/ambiente/ecologia_politica.html

Intergovernmental Panel on Climate Change. http://www.ipcc.ch/publications and_data/ar4/syr/en/spm.html

International Federation of Red Cross Red Crescent Societies. http://www.ifrc. org/publicat/wdr2001/

KEMPF, Hervé. Como os ricos destroem o planeta. Trad. Bernardo Ajzenberg. São Paulo: Globo, 2010

LATOUCHE, Serge Pequeno Tratado do Decrescimento Sereno. Trad. Cláudia Berliner. São Paulo, Edições 70, 2011

LEITE, José Rubens Morato; AYALA, Patrick de Araújo. Dano ambiental: do individual ao coletivo extrapatrimonial. 3. ed. Ver. atual. e ampl. São Paulo: Editora Revista dos Tribunais, 2010.

LEITE, José Rubens Morato. Sociedade de Risco e Estado. In CANOTILHO, 
José Joaquim Gomes; LEITE, José Rubens Morato (orgs.). Direito Constitucional Ambiental Brasileiro 2. ed. rev. São Paulo: Saraiva, 2008.

LOVELOCK, James. Gaia: alerta final. Trad. Vera de Paula Assis, Jesus de Paula Assis. Rio de Janeiro: Intrínseca, 2010

LÖWY, Michael. Ecologia e socialismo. São Paulo: Cortez, 2005.

MARENGO, José A. Mudanças climáticas globais e seus efeitos sobre a biodiversidade: caracterização do clima atual e definição das alterações climáticas para o território brasileiro ao longo do século XXI. Brasília: MMA, 2006.

MORIN, Edgar; KERN. Anne-Brigitte. Terra-Pátria. Trad. Paulo Azevedo Neves da Silva, 5. ed. Porto Alegre: Sulina, 2005

PORTO-GONÇALVES, Carlos Walter. O desafio ambiental. Rio de Janeiro: Record, 2004.

REPÚBLICA DE BOLIVIA. Constituicion Politica del Estado, 2009.

SANTILLI, Juliana. Socioambientalismo e novos direitos. São Paulo: Peirópolis, 2005.

SANTOS, Boaventura de Sousa. Hablamos Del Socialismo del Buen Vivir. http://www.alames.org/documentos/socialismoboav.pdf

\section{PLANETARY CRISIS, ENVIRONMENTAL STATE AND ECOSOCIALISM}

Abstract: This paper aims at discussing the impacts of current global environmental crisis on human society and law. Intends, with this, from what it conceives of a planetary crisis, with characteristic "policrisis" look at how the environmental movement and how it reacted influenced the law, in particular, Environmental Law, in dialogue with the new finally proposal of ecological socialism or eco-socialism. The claim of the article is not, obviously, exhaust the subject, which is brand new in the social sciences, especially in law, but merely to approximate like the concepts of State for Environmental Law and Ecosocialism. All with a view to overcoming the crisis that humanity - life as a whole - is steeped today.

Keywords: Environmental Crisis. Law. Ecosocialism.

Data de recebimento: nov/2010 - Data de aprovação: jan/2011 